\title{
Visual evoked potentials in Parkinsonism and dopamine blockade reveal a stimulus-dependent dopamine function in humans
}

\author{
M ONOFRJ,* MF GHILARDI, $\dagger$ M BASCIANI,* D GAMBI* \\ From the Departments of Neurology of the University of Chieti, ${ }^{*}$ and University of Milan (Clinica Neurologica \\ IV, HS Raffaele $), \dagger$ Italy
}

SUMMARY VEPs were recorded with three different spatial frequencies of stimulation in patients affected by idiopathic Parkinsonism and by Parkinsonian syndromes. The detection of VEP abnormalities in Parkinson's disease was dependent on the spatial frequency of the visual stimulus (a vertical square wave grating). The VEP latency was normal in Parkinsonian syndrome patients (except in one patient affected by familial Parkinsonism). Dopamine precursor therapy differently reduced the VEP latency, depending on the spatial frequency of the visual stimulus. These findings suggest that the dopaminergic mechanism involved in the generation of VEP delays is sensitive to stimulus spatial frequency. The study of VEPs before and after the administration of haloperidol confirmed this hypothesis. VEP latency did not correlate with the major clinical symptoms of Parkinson's disease and could not predict the results of chronic dopaminergic therapy.

Since pattern visual evoked potential (VEP) measurement was introduced as a reliable diagnostic tool in multiple sclerosis, ${ }^{1}$ a number of studies have reported VEP alterations in other neurological diseases. ${ }^{2-6}$ These VEP latency delays were attributed to slowing of central conduction reflecting optic nerve demyelination. ${ }^{2-5}$ More recently, VEP studies have been extended to include patients with Parkinson's disease. Observed VEP delays in Parkinson's disease $^{6-9}$ are unlikely to be due to the slowing of conduction in the optic pathways. ${ }^{6}$ Furthermore, a reduction of these VEP latencies by levodopa preparations ${ }^{67}$ suggests that the delays in Parkinson's disease might be due in part to dopamine deficiency and thus akin to the major clinical deficits of Parkinsonism. Prolonged VEPs in over $50 \%$ of Parkinson's disease patients have been described in several independent studies, ${ }^{6-11}$ while others found delays only in $20 \%$ of the patients. ${ }^{12}$ Normal VEPs were reported in other studies, ${ }^{13-16}$ and some researchers found only VEP amplitude reductions ${ }^{17}$

Address for reprint requests: Dr Marco Onofrj, Clinica Neurologica, University of Chieti, Osp Pediatrico, 66100 Chieti, Italy.

Received 26 April 1985 and in revised form 4 November 1985. Accepted 5 December 1985 or VEP asymmetries. ${ }^{18}$

A wide variety of stimulus conditions were used in these studies. The visual stimuli ranged from uniform field stimulation ${ }^{15} 18$ to checks or gratings of differing spatial frequencies. ${ }^{6-141617}$ In addition, VEPs were recorded prior to dopamine precursor treatment in some studies ${ }^{671119}$ or only during treatment in others $8-10131617$ or in unspecified conditions in others. ${ }^{1214}$ Thus much controversy still persists about the VEP in Parkinson's disease.

Our study was aimed at interpreting the discrepant VEP findings in Parkinson's disease. Gratings with elements subtending three different widths of visual angle were used for pattern stimulation, and VEPs were recorded in patients affected by Parkinson's disease of different severity. VEP data were collected before and during treatment, as well as during periods off drugs ${ }^{20}$ for therapy adjustment. In six patients, VEPs were recorded during transient dyskinetic episodes. We further attempted to correlate VEP abnormalities with any sign or complex of signs of Parkinsonism. Finally, in order to determine if the VEP latency abnormalities, as observed in Parkinson's disease patients, could also be produced by drug administration, we studied non-Parkinsonian patients before and after dopamine blocker (haloperidol) therapy, using gratings with different pattern element sizes. 
Methods

\section{(a) Controls}

Normative data were obtained by recording VEP to monocular stimuli in 58 healthy volunteers (age range 20-75 years) with normal ocular media and normal visual acuity.

In a preliminary study, the relationship between latency of VEP and age of the controls was tested for each spatial frequency using the Pearson's $r$ coefficient. The linear regressions of VEP latencies of 1, 2 and 4 cycles per degree grating stimulation against age were all statistically significant at the 0.001 level. VEP data of Parkinson's disease and Parkinsonian syndrome patients were therefore compared only with data of 30 subjects of the control group having a corresponding age range (range 52-75, mean 64.58 \pm 5.9 years). This broad age span was selected since the $99 \cdot 5 \%$ confidence limit of 52-65 and 65-75 years old normal controls were identical.

In 18 subjects ( 10 of the age range $24-48$ and 8 of ages 54-68 yr) VEPs were recorded 2-4 times in a 1-16 week period. The measurements recorded in these subjects were used to calculate a normal range of variability and to evaluate the significance of VEP latency variation induced by chronic dopamine precursor therapy.

\section{(b) Patients and testing procedures}

Idiopathic Parkinson's disease. Twenty eight patients (16 female and 12 males) affected by Parkinson's disease, duration from 1 to 9 years (mean $4 \pm 2$ ), were selected for the study from 82 inpatients and outpatients of the neurology department. In the selected patients, ophthalmoscopic examination, including inspection of the ocular media or retinae, and intraocular pressure by tonometry, was normal. Visual acuity was corrected for $57 \mathrm{~cm}$ viewing distance. The subjects had to be able to fixate the centre of the stimulating screen when adequate correction was achieved, and reproduceable VEP traces had to be obtained with identifiable P100. The mean age of the patients was $61 \cdot 3$ \pm 5.6 (range 52-74) years. Using the Hoehn and Yahr's classification, ${ }^{21}$ six of these patients were at stage $I ; 12$ at stage II; seven at stage III; three at stage IV.

VEPs were recorded in five patients in stage I before treatment and 8-14 days after the initiation of dopamine precursor therapy (Sinemet $250=1$ bolster contains $250 \mathrm{mg}$ levodopa $+25 \mathrm{mg}$ carbidopa). The remaining patients were currently receiving various treatments with anticholinergics, amantadine, dopamine precursors or bromocriptine. All these patients were hospitalised to evaluate the effects of therapy adjustments. The drug dosage was gradually reduced and eventually discontinued, ${ }^{22}$ with a drug free period of at least 48 hours before the first VEP recording session. In these patients, VEPs were again recorded 5-7 days after the initiation of Sinemet therapy. Results of this study are considered as effects of "chronic dopamine precursor administration".

In ten of the Parkinson's disease patients (three at stage I, five at stage II, two at stage III), VEPs were studied before and after the oral acute administration of half a bolster of Sinemet 250 . This drug dose was selected since, in preliminary studies, some of the patients experienced nausea when a Sinemet 250 bolster was administered. These results are reported in the section "effect of acute dopamine precur- sor administration". In all the Parkinson's disease patients, the Parkinsonian symptoms were rated hourly on the scale of the "Clinical Center for Research in Parkinson's and Allied Diseases" 20 with the purpose of further elucidating the relationship of VEP latency delays and the clinical picture of Parkinsonism. Tremor (scale $0-4$ for each limb), rigidity (scale $0-4$ for each limb), bradykinesia (scale $0-4$ ) and gait disturbance (scale 0-4) were reported for each patient before and after 5-7 days treatment with Sinemet. In two stage II and three stage III patients, VEP studies were performed prior to the drug wash-out period, when the patients were experiencing transient oscillations of their clinical status. These transient disturbances were of the "end-start dose failure" or "wearing-off" kind. ${ }^{20}$ VEPs were studied during the wearing-off akinesia state, and when the patients had overcome the akinetic period, as assessed by the hourly rating scale.

Parkinsonian Syndromes. Six other patients, considered outside the group of "idiopathic Parkinsonism" were similarly studied. Two Parkinsonian syndrome subjects (one male 67 years old and one female 72 years old) were affected by arteriosclerotic pseudo-Parkinsonism. Two male patients, ages 59 and 67 , were classified as having progressive supranuclear palsy; in a 59-year-old female a diagnosis of multiple system atrophy, probably of the olivopontocerebellar atrophy (OPC) type, was made. The last patient, a 56-year-old female, was affected by autosomal dominant familial Parkinsonism; she presented with a predominant akinetic-rigid symptomatology which responded to Sinemet treatment.

Haloperidol study. In eight patients, ages 24-36, each with an acute paranoid state, VEPs to 1, 2 and 4 cycles per degree (cpd) grating stimulation were recorded before and after administration of $6 \mathrm{mg}$ IV haloperidol (in three different doses). The VEP latencies and amplitudes were compared with data of the 28 control subjects of the same age range $(31.6 \pm 6 \cdot 8$ years). In four of these patients, VEPs were also recorded using $0.5 \mathrm{cpd}$ grating.

\section{(c) Stimulus and recording apparatus}

VEPs were recorded in an electrically shielded dark room of $2 \times 4 \mathrm{~m}$. The pattern generator, amplifiers and averaging system were part of an Amplaid MK 6 Evoked Potential recording unit. Vertical gratings with a square wave luminance profile were presented on the screen of the Amplaid monitor. The monitor was placed at $57 \mathrm{~cm}$ from the observer's eye. The border of the screen was covered with an opaque mask of $6 \mathrm{~cm}$ width. The central stimulating part of the screen subtended $18^{\circ}$ of the observer's visual angle. The mean luminance was $65 \mathrm{~cd} / \mathrm{m}^{2}$. The contrast, defined as the ratio of the difference of maximum and minimum luminances of adjacent bands over their summed luminances, was $50 \%$. We calibrated the minimum and the maximum luminances by means of a Centronic Photodiode photometer for all the spatial frequencies tested. The patients were requested to fixate a central horizontal $0.5 \times 0.2 \mathrm{~cm}$ bar. Fixation was continously monitored by the examiner. Three different spatial frequencies of the grating pattern were used in the study of Parkinson's disease patients. The lowest spatial frequency was $1 \mathrm{cpd}$, that is the width of each element of the grating pattern was $30^{\prime}$ of arc at the eye. The intermediate spatial frequency was of $2 \mathrm{cpd}$, corresponding to $15^{\prime}$ 
of arc bar width; the highest spatial frequency was $4 \mathrm{cpd}$, corresponding to $7 \cdot 5^{\prime}$ of arc bar width. In four patients of the haloperidol study group, a spatial frequency of $0.5 \mathrm{cpd}$ was also used. The contrast of the grating was reversed (that is dark bars become bright and vice versa) every $625 \mathrm{~ms}$. The temporal waveform was a square wave. In all the recording sessions, the screen was viewed monocularly by either eye, while the other eye was patched. In the study of patients having "wearing-off" 20 symptoms, the screen was viewed binocularly and only 2 and $4 \mathrm{cpd}$ stimuli were used. VEPs were recorded with a silver disk surface electrode placed 4 $\mathrm{cm}$ above the inion. A reference disk electrode was placed in the Queen's Square midfrontal position ${ }^{2}$ and the ground electrode was located at the vertex. Potentials recorded at the active occipital electrode were amplified 20000 times. Bandpass filters were set at $1-50 \mathrm{~Hz}$. The analysis time was $300 \mathrm{~ms} ; 128-256$ sweeps were averaged on the Amplaid MK 6 unit (512 memory point resolution per channel, $580 \mu \mathrm{s}$ sampling rate). Two or three traces were obtained for each stimulating pattern and the latency of the major positive component $^{1}$ was measured using the computer cursor. The VEP amplitude was measured in microvolts $(\mu \mathrm{V})$ from the peak of the early negative wave ${ }^{12}$ to the peak of the major positive deflection. A temporal trigger from the computer drove the stimulus generator and the averager.

\section{(d) Statistical study}

In Parkinson's disease and other patients, the VEPs recorded at the various spatial frequencies of stimulation were considered delayed when the latency of the major positive component was above the value of the mean plus 2.7 standard deviations ( $99.5 \%$ level of certainty for upper limits of latency, based on the results of 30 age matched controls, 60 eyes). The VEP latencies and amplitudes of all controls and patients, prior to and following pharmacological treatment, age, disease stage and duration, as well as symptoms including tremor, rigidity, bradykinesia and gait scores prior to and post treatment were also entered into a PDP 11/45 computer. The CLINFO Data Management and Analysis System (Bolt Baranek and Newman Inc., Cambridge, Mass.) program was employed.

Linear and multiple regressions, $t$ tests and one-way Analyses of Variance (ANOVA) were performed using VEP data from the three spatial frequency patterns. VEP data, both pre- and post-dopamine precursor treatment, were compared with clinical scores (both initial and post-treatment), age, and disease stage and duration. The effect of haloperidol was similarly evaluated. Multiple correlations were also performed on VEP data of the 10 patients undergoing acute dopamine precursor administration. Any significant correlation between these data would indicate that VEP changes after a single dose of Sinemet could be used to predict the results of dopamine precursor therapy in these patients.

\section{Results}

\section{(a) Controls}

The mean latency and amplitude measurements of VEPs obtained with stimuli of 1,2 and $4 \mathrm{cpd}$ to each eye, and the mean interocular latency differences in the two control groups (ages 20-48 and 52-75) are listed in table 1. The major positive wave latency in individual control subjects at each spatial frequency did not vary by more than $4 \mathrm{~ms}$ when recorded on the same day. Where testing sessions were separated by weeks, the broadest variations for the latency of the major positive peak was \pm 9 ms. The mean of latency variability was $3.84 \pm 2.58 \mathrm{~ms}$. The $99.5 \%$ confidence limit of interocular latency differences was $9 \mathrm{~ms}$, inde-

Table 1 Normal controls mean values of VEPs recorded with three different spatial frequencies of stimulation

\begin{tabular}{|c|c|c|c|c|c|c|}
\hline & $1 \mathrm{cpd}$ & $I O D$ & $2 c p d$ & $I O D$ & $4 c p d$ & $I O D$ \\
\hline Lat. G 1 & $\begin{array}{l}106.9 \pm 6.1 \\
\quad(124)\end{array}$ & $2.8 \pm 1.6$ & $\begin{array}{c}110.6 \pm 6.5 \\
(129)\end{array}$ & $2 \cdot 7 \pm 1 \cdot 5$ & $\begin{array}{c}119.4 \pm 5.9 \\
(136)\end{array}$ & $2 \cdot 5 \pm 1 \cdot 2$ \\
\hline Lat. G 2 & $\begin{array}{c}112.5 \pm 5.6 \\
(129)\end{array}$ & $3.3 \pm 1.7$ & $\begin{array}{c}116 \cdot 1 \pm 5 \cdot 2 \\
(131)\end{array}$ & $2.6 \pm 1.7$ & $\begin{array}{c}126.9 \pm 5.0 \\
(141)\end{array}$ & $2.6 \pm 1.8$ \\
\hline $\begin{array}{l}\text { Amp. G } 1 \\
\text { Amp. G } 2\end{array}$ & $\begin{array}{l}7.7 \pm 1.8 \\
7.0 \pm 2.0\end{array}$ & $\begin{array}{l}1.1 \pm 0.8 \\
1.3 \pm 0.8\end{array}$ & $\begin{array}{l}7.8 \pm 1.9 \\
6.6 \pm 1.8\end{array}$ & $\begin{array}{l}0.9 \pm 0.7 \\
0.9 \pm 0.8\end{array}$ & $\begin{array}{l}4.3 \pm 1.0 \\
3.3 \pm 0.9\end{array}$ & $\begin{array}{l}0.6 \pm 0.5 \\
0.7 \pm 0.6\end{array}$ \\
\hline
\end{tabular}

Lat. means latency values in ms. Amp are amplitude values in $\mu \mathrm{V}$. IOD is the interocular difference of latencies and amplitudes. Decimal values are approximated to the first digit. G 2 is the control group of the same age range as Parkinson's disease patients. G 1 is the control group aged 20-48 years. \pm indicates one standard deviation of the normal mean. In parenthesis the $99.5 \%$ confidence upper limits.

Table 2 Mean values and percentage VEP latency abnormalities in idiopathic Parkinson's disease patients before and after levodopa + carbidopa treatment

\begin{tabular}{|c|c|c|c|c|c|c|}
\hline & Lat $1 c$ & Lat 2 cpd & Lat $4 \mathrm{cpd}$ & Amp 1 cpd & Amp $2 c p d$ & Amp $4 c p d$ \\
\hline $\begin{array}{l}\text { Before } \\
\% \text { abnormal VEP } \\
\text { After } \\
\% \text { abnormal VEP }\end{array}$ & $\begin{array}{l}122 \cdot 6 \pm 10 \cdot 3 \\
39 \% \\
121 \cdot 4 \pm 8 \cdot 7 \\
28 \%\end{array}$ & $\begin{array}{l}130.6 \pm 12.8 \\
50 \% \\
125.9 \pm 9.7 \\
28 \%\end{array}$ & $\begin{array}{l}141 \cdot 7 \pm 12 \cdot 9 \\
60 \% \\
134 \cdot 3 \pm 8 \cdot 1 \\
32 \%\end{array}$ & $\begin{array}{l}6 \cdot 2 \pm 1 \cdot 4 \\
\frac{6 \cdot 4}{-} \pm 1 \cdot 3\end{array}$ & $\begin{array}{l}5 \cdot 6 \pm 1 \cdot 3 \\
\frac{6 \cdot 0}{-} \pm 1 \cdot 2\end{array}$ & $\begin{array}{l}2.6 \pm 0.7 \\
\frac{2.5}{-} \pm 0.7\end{array}$ \\
\hline
\end{tabular}

$\%$ abnormal VEP indicates the percentage of patients in whom either a VEP delay or an increment of interocular latency difference was detected. Latency and amplitude measurement as in table 1. 
Table 3 Percentage of patients having VEP abnormalities in relation to the Parkinson's disease stage

\begin{tabular}{|c|c|c|c|c|c|c|}
\hline & \multicolumn{2}{|c|}{$1 \mathrm{cpd}$} & \multicolumn{2}{|l|}{$2 c p d$} & \multicolumn{2}{|l|}{$4 c p d$} \\
\hline & $\boldsymbol{B}$ & $A$ & $B$ & $A$ & $B$ & $A$ \\
\hline $\begin{array}{l}\text { Stage I } \\
\text { Stage II } \\
\text { Stage III } \\
\text { Stage IV }\end{array}$ & $\begin{array}{l}16 \% \\
41 \% \\
42 \% \\
66 \%\end{array}$ & $\begin{array}{l}16 \% \\
16 \% \\
28 \% \\
66 \%\end{array}$ & $\begin{array}{l}32 \% \\
58 \% \\
42 \% \\
66 \%\end{array}$ & $\begin{array}{l}16 \% \\
25 \% \\
28 \% \\
66 \%\end{array}$ & $\begin{array}{l}32 \% \\
66 \% \\
42 \% \\
66 \%\end{array}$ & $\begin{array}{l}16 \% \\
33 \% \\
28 \% \\
66 \%\end{array}$ \\
\hline
\end{tabular}

Stage classification according to the Hoehn and Yahr's method. ${ }^{20}$ $B=$ in untreated conditions. $A=$ after the initiation or the resumption of a levodopa + carbidopa treatment.

pendent of the age of subjects and of the spatial frequency of stimulation.

\section{(b) Idiopathic Parkinson's disease patients}

Table 2 shows data of Parkinson's disease patients in drug free state and after the initiation or resumption of a dopamine precursor therapeutic regimen. The table also shows the percentage of Parkinson's disease patients in whom delayed VEPs or increments of interocular latency differences were detected. Abnormally high values of interocular latency difference with normal absolute VEP latencies were detected in only two patients with $1 \mathrm{cpd}$ stimuli, in three patients with 2 and $4 \mathrm{cpd}$ stimuli. A VEP abnormality was generally manifest as a prolonged latency of the major positive wave either in only one eye (in two patients for $1 \mathrm{cpd}$, three patients for $2 \mathrm{cpd}$, five patients for $4 \mathrm{cpd}$ ) or in both eyes (seven patients for $1 \mathrm{cpd}$, eight patients for 2 and $4 \mathrm{cpd}$ ). It is evident from table 3 that VEPs to $4 \mathrm{cpd}$ stimuli were delayed in a larger number of patients than VEPs to 1 and 2 cpd stimuli. "Chronic" dopamine precursor treatment reduced the VEP latencies to normal limits in almost one third of the affected patients. This effect, as can be seen in table 2 , is dependent on the spatial frequency. The drug response is most evident when $4 \mathrm{cpd}$ gratings are used. Reductions of VEP latencies after Sinemet therapy were detected in 21 and 22 patients when 2 and 4 cpd were used; when the $1 \mathrm{cpd}$ stimulus was used, VEP latency reductions were recorded only in 12 patients (42\%). The decrement of VEP latencies after treatment was above the $99.5 \%$ confidence limit for latency variability (for VEP recordings performed weeks apart) in 15 out of 56 eyes for $4 \mathrm{cpd}$ stimuli, in seven eyes for $2 \mathrm{cpd}$ stimuli and in one eye for $1 \mathrm{cpd}$ stimuli. In the patients with abnormal VEPs during Sinemet treatment, the abnormality was present for all the tested spatial frequencies of stimulation, except in one case. Figure 1 clarifies the spatial frequency dependence of VEP delay in Parkinson's disease and the different effect of Sinemet administration on the latency of VEPs obtained with different spatial frequencies. One-way ANOVAs of VEP latencies and amplitudes (control VEPs vs Parkinson's disease "untreated" VEPs, control VEPs vs Parkinson's disease "treated" VEPs, Parkinson's disease "untreated" VEPs vs Parkinson's disease "treated" VEPs) showed that VEP latencies of Parkinson's disease patients were significantly different from controls $(p=0.05$ or less for all comparisons) and that only 2 and $4 \mathrm{cpd}$ latencies of "untreated" Parkinson's disease patients were different from VEP latencies from "treated" Parkinson's disease patients $(p<0.02)$.

Linear regressions of VEP latencies and amplitudes vs the age of Parkinson's disease patients and the duration of Parkinson's disease did not reach statistical significance.

The stage $^{20}$ of Parkinson's disease was not significantly correlated with the VEP measurements at any of the stimulated spatial frequencies. Figure 2

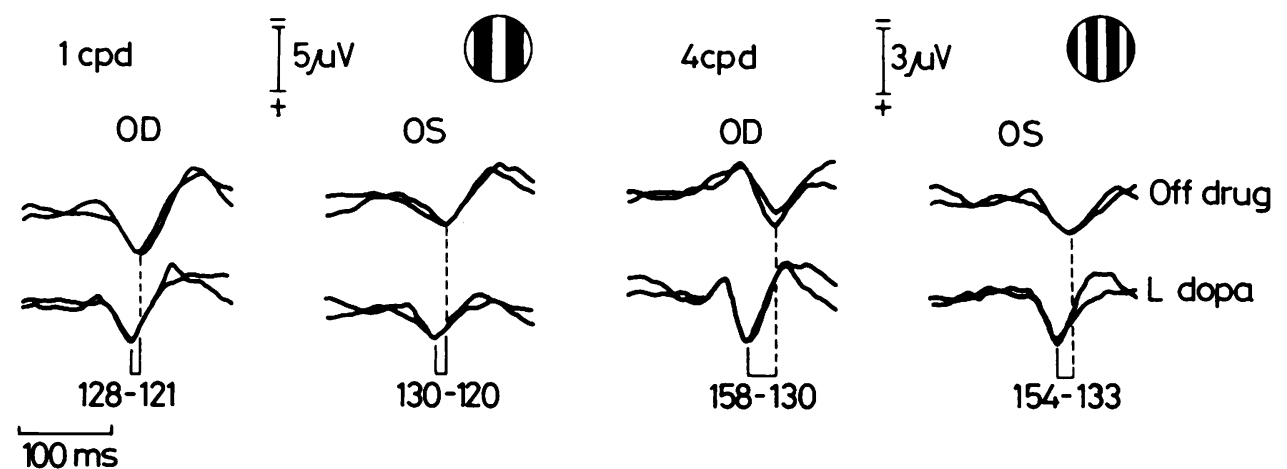

Fig 1 VEPs obtained with two different spatial frequency gratings ( 1 and $4 \mathrm{cpd}$ ) from the right (OD) and left (OS) eyes of a Parkinson's disease patient. Compare the VEP latencies before (off drug) and following the administration of $750 \mathrm{mg}$ levodopa + carbidopa daily. The $99.5 \%$ confidence limit of the latency is 129 ms for $1 \mathrm{cpd} V E P s$ and $141 \mathrm{~ms}$ for $4 \mathrm{cpd} V E P s$. 


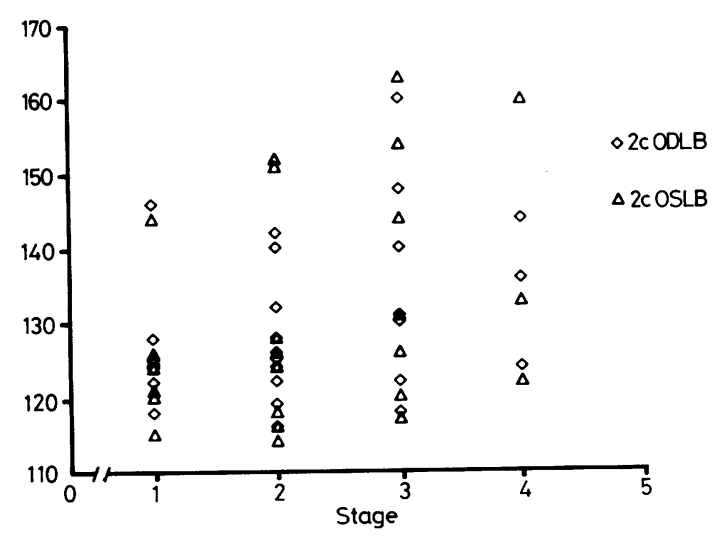

Fig 2 Scattergram of VEP latencies using 2 cpd grating vs the stage of Parkinson's disease patients. 2CODLB and $2 c O S L B$ indicates latency of right and left eyes VEPs respectively to 2 cpd stimulation before the dopamine precursor treatment. The $99.5 \%$ confidence limit for $2 \mathrm{cpd}$ $V E P s$ is $131 \mathrm{~ms}$.

shows a scattergram of VEP latencies recorded with 2 cpd stimuli prior to Sinemet treatment from the left and right eyes of Parkinson's disease patients plotted against the stage of the disease. The multiple correlation coefficients for stage vs VEP latencies were not significant for 1,2 , or 4 cpd prior to or following treatment. Table 3 shows the percentage of patients of various Parkinson's disease stages whose VEPs were abnormal before and after Sinemet treatment. These data show that the VEP latency fell within the normal limits following dopamine precursor treatment in a larger number of stage I and II Parkinson's disease patients than those in stage III and IV. However, $t$ test comparisons between the VEP latencies of patients in stages I and II vs stages III and IV group patients both pre- and post-treatment were not statistically significant.

The evaluation of major Parkinson's disease clinical symptoms based on the hourly rating scale gave the following results: tremor, mean value $4.5 \pm$ $2 \cdot 2$, range $1-9$; rigidity, mean value $2 \cdot 2 \pm 0 \cdot 9$, range $1-4$; gait, mean value $2 \cdot 0 \pm 1 \cdot 0$, range $0-4$. Following the initiation or resumption of Sinemet therapy, the mean values of clinical scores were: tremor, $3 \cdot 6 \pm 2 \cdot 3$; rigidity, $3 \cdot 8 \pm 2 \cdot 5$; gait $1 \cdot 8 \pm 1 \cdot 1$. The results of multiple linear regressions for clinical scores vs VEP latencies and amplitudes were statistically significant for only the pre-treatment bradykinesia score vs $1 \mathrm{cpd}$ pre-treatment VEP latency $(\mathrm{p}=0.011)$. Moreover, pre-treatment bradykinesia scores correlated at the 0.003 level with the pre-treatment latencies of VEPs obtained with $1 \mathrm{cpd}$ stimuli of the left eyes. The levels of significance of all other correlations (comparison

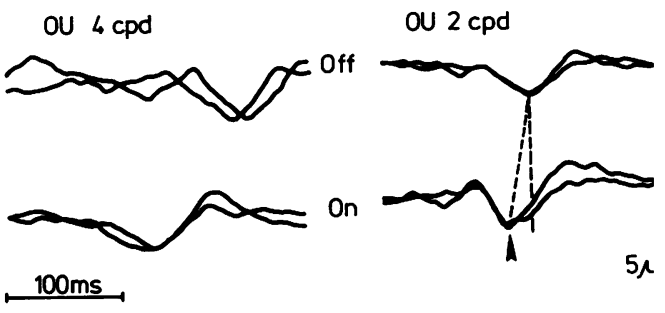

Fig 3 VEPs recorded during akinetic episodes. The grati element size are $4 \mathrm{cpd}\left(7 \cdot 5^{\prime}\right)$ and $2 \mathrm{cpd}\left(15^{\prime}\right)$. The screen $\mathrm{n}$ viewed binocularly $(O U)$. Notice the latency increment of $V E P$ secorded in $O F F$ (wearing off) phases. In OFF conditions the $7 \cdot 5^{\prime}$ grating does not evoke reliable response

between clinical scores and VEPs, both pre- and pc treatment) ranged from 0.058 (tremor reduction pre-treatment VEP latency) to 0.556 (pre-treatm gait score vs pre-treatment VEP latency). Normal delayed VEPs could be found in patients having si lar clinical scores for any of the major clinical syr toms considered; and conversely, markedly dela latencies were detected in patients classified in the tial stage of the disease with modest symptoms as $\mathbf{v}$ as in patients severely affected. The statistical cc parisons of VEP latencies and clinical scores and $\mathbf{F}$ kinson's disease stages show therefore that $\mathrm{V}$ latencies can not be used to predict the responsiver. to treatment of Parkinson's disease patients and not facilitate a classification of subgroups of Park son's disease.

Peak dose dyskinesia was detected in four patie after the administration of Sinemet. Three of th patients had abnormal VEPs prior to treatment wh persisted in two after treatment. Mean VEP value: these patients were not different from VEP values the other Parkinson's disease patients.

The study of six patients experiencing wearing akinetic symptoms during the off-phase, which dis peared during the on-phase, revealed that VEP lat cies could similarly fluctuate. Figure 3 shows example of binocular VEP recordings to 2 and 4 , gratings in the same patient during a wearing-off riod and when the transient akinesia had disappeal In these six patients, the VEP amplitudes either cremented or decremented with off or on phases spectively. The VEP latencies, however decrea from off to on phases by as much as 17 ms (mean 1 $\pm 2.8 \mathrm{~ms}$ for $4 \mathrm{cpd}, 7.9 \pm 4.5 \mathrm{~ms}$ for $2 \mathrm{cpd}$ ).

(c) Effect of acute dopamine precursor administrat In the 10 Parkinson's disease patients selected for acute dopamine study, the mean age was $59.1 \pm$ years, the mean Parkinson's disease duration was \pm 1.9 years. Mean pre-treatment clinical scores $v$ 
Table 4 Comparison of VEP measurement in untreated conditions after chronic dopamine precursor treatment and after a single dose of dopamine precursor

\begin{tabular}{|c|c|c|c|c|c|c|}
\hline & Lat $1 \mathrm{cpd}$ & Lat 2 cpd & Lat $4 c p d$ & Amp 1 cpd & Amp $2 c p d$ & $A m p 4 c p d$ \\
\hline $\begin{array}{l}\text { Pretreatment } \\
\text { Chronic treatment } \\
\text { Acute levodopa }\end{array}$ & $\begin{array}{l}125.7 \pm 12.1 \\
124.2 \pm 10.9 \\
122.8 \pm 9.7\end{array}$ & $\begin{array}{l}137.0 \pm 14.9 \\
130.1 \pm 13.1 \\
131.2 \pm 11.6\end{array}$ & $\begin{array}{l}149.2 \pm 14.8 \\
138.2 \pm 11.3 \\
143.1 \pm 11.9\end{array}$ & $\begin{array}{l}5.9 \pm 1.1 \\
6.1 \pm 1 \cdot 1 \\
5.9 \pm 1 \cdot 1\end{array}$ & $\begin{array}{l}5.2 \pm 1.1 \\
5.7 \pm 1.0 \\
5.4 \pm 1.2\end{array}$ & $\begin{array}{l}2.3 \pm 0.5 \\
2.4 \pm 0.7 \\
2.4 \pm 0.5\end{array}$ \\
\hline
\end{tabular}

The table reports VEP measurement in a group of 10 Parkinson's disease patients in untreated conditions (pretreatment), after the chronic administration of adequate Sinemet doses (chronic treatment) and 10-30 min after a single half dose of Sinemet 250 (acute levodopa).

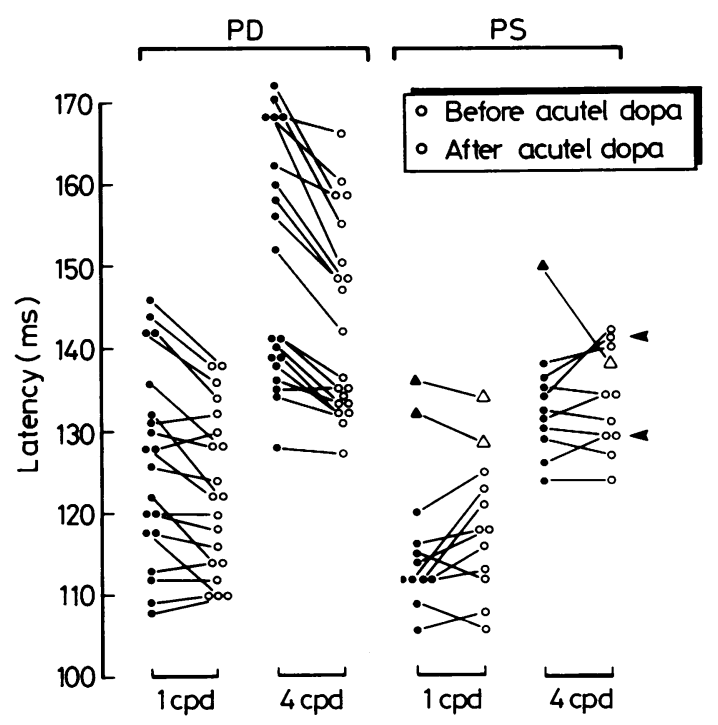

Fig 4 Scattergram of VEP latencies obtained with 1 and 4 cpd gratings before and 10-30 min after the administration of a single dose of levodopa + carbidopa $(125 \mathrm{mg})$ in two groups of patients: idiopathic Parkinson's disease, and Parkinsonian syndromes, (supranuclear progressive paralysis, arteriosclerotic pseudo-Parkinsonism, olivopontocerebellar atrophy). the triangular symbol represents the data of a patient affected by familial Parkinsonism. Only one symbol for this patient is reported at $4 \mathrm{cpd}$, since VEPs at this frequency could not be recorded from the left eye. The arrows on the right point to the $99.5 \%$ confidence limit of latency for these two frequencies (141 $m s-4 c p d, 129 m s-1$ cpd).

$4.8 \pm 2 \cdot 1$ for tremor, $3.6 \pm 1 \cdot 5$ for rigidity, $1.9 \pm 0.7$ for bradykinesia and $1.7 \pm 0.9$ for gait. The chronic levodopa treatment reduced the clinical scores to 3.8 \pm 2.8 for the tremor, $2.8 \pm 1.2$ for rigidity, $1.6 \pm 0.9$ for bradykinesia and $1.6 \pm 0.8$ for gait. Table 4 reports the mean VEP latencies and amplitudes for these patients before and after a single dose of $125 \mathrm{mg}$ levodopa (Sinemet 250, half bolster) and after the chronic administration of levodopa + carbidopa. The Sinemet administration acutely reduced VEP latencies in these patients by $1-15 \mathrm{~ms}(7.8 \pm 3.5 \mathrm{~ms})$ when 4 and $2 \mathrm{cpd}$ stimuli were used and by $2-10 \mathrm{~ms}$ $(6 \cdot 1 \pm 2.5 \mathrm{~ms})$ when $1 \mathrm{cpd}$ was used. Only $10 \mathrm{VEPs}$, out of 60 tested eyes, showed no significant increments (1-4 ms) or no change. On the left half of fig 4 , the results of VEP latencies to 1 and $4 \mathrm{cpd}$ stimuli before and after the acute administration of Sinemet in Parkinson's disease are shown as a scatterplot.

VEP latency reductions after acute Sinemet dosage were found to be statistically significant $(p<0.001)$ for all the tested spatial frequencies using a one-way ANOVA. The VEP amplitude differences between untreated vs acute Sinemet were also statistically significant, but only at $4 \mathrm{cpd}(\mathrm{p}<0.001)$. The ANOVAs for VEP latencies and amplitudes measured in these 10 Parkinson's disease patients during the period of chronic treatment with Sinemet and the acute administration of Sinemet did not reach statistical significance. The linear regression was calculated using VEP latency reductions (difference between preand post-Sinemet VEP latency) vs the clinical scores of the major Parkinsonian symptoms in the untreated condition. Linear regression analysis was also performed between VEP latency reductions and the reductions of clinical scores due to chronic levodopa + carbidopa treatment. None of these tests was statistically significant.

\section{(d) Parkinsonian syndromes}

Figure 4 displays VEP latencies obtained with 1 and 4 cpd stimuli for six Parkinsonian syndrome patients. Only the 6th patient (probably affected by familial Parkinsonism) had abnormal VEP latencies (132 ms right eye, $136 \mathrm{~ms}$ left eye for $1 \mathrm{cpd}$ stimuli; $135 \mathrm{~ms}$ right eye, $138 \mathrm{~ms}$ left eye for $2 \mathrm{cpd} ; 150 \mathrm{~ms}$ right eye while responses with identifiable major positive peaks were unobtainable at $4 \mathrm{cpd}$ in the left eye). All the other patients had VEP latency and amplitude values within the $99 \%$ confidence limit of the age matched control group.

The administration of a single oral dose of Sinemet 125 induced a reduction of VEP latencies in the 6th patient. In the other patients, the same dose induced either response variability which remained within normal limits or a clear increment of VEP latencies of 6 to $11 \mathrm{~ms}$. VEP amplitudes did not show consistent modifications. 


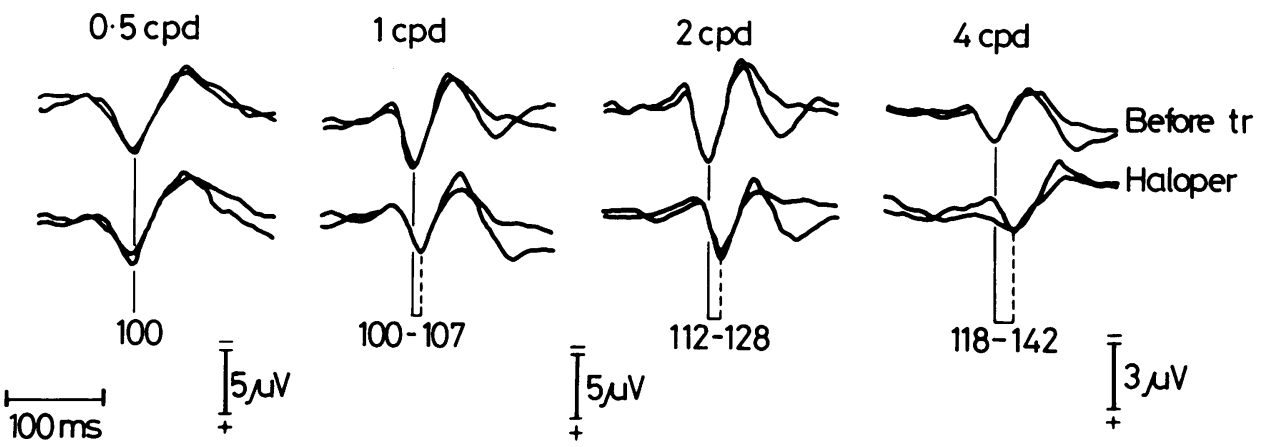

Fig 5 VEPs to different spatial frequencies recorded from the right eye of a patient with atypical paranoid disorder before treatment and after (haloperidol) the IV administration of $6 \mathrm{mg}$ haloperidol. Note the differential effect of haloperidol on VEPs obtained at increasing spatial frequencies.

\section{(e) Haloperidol study}

In all eight patients, the administration of IV haloperidol $(4 \mathrm{mg})$ induced an increment of VEP latencies which was most evident when 2 and $4 \mathrm{cpd}$, rather than $1 \mathrm{cpd}$ stimuli, were used. Figure 5 highlights the relationship between spatial frequency and VEP latency increment after haloperidol administration. The mean latency values for VEPs obtained before treatment from the left and right eyes of the patients were $103.5 \pm 3.3 \mathrm{~ms}$ for $1 \mathrm{cpd}$ stimuli, $105.4 \pm 3.9 \mathrm{~ms}$ for 2 cpd stimuli and 117.2 \pm 4.4 ms for 4 cpd stimuli. The mean amplitude values in pre-treated conditions were $6.4 \pm 1.1 \mu \mathrm{V}, 6.6 \pm 1.2 \mu \mathrm{V}$ and $3.1 \pm 0.6 \mu \mathrm{V}$ for 1,2 and $4 \mathrm{cpd}$ respectively. In four patients $0.5 \mathrm{cpd}$ gratings were also used and mean VEP latency was $103 \cdot 1 \pm 3.2 \mathrm{~ms}$ with a mean amplitude of $6.5 \pm 1 \cdot 2$ $\mu \mathrm{V}$.

After haloperidol administration, the mean VEP latencies were $106.4 \pm 4.7 \mathrm{~ms}(1 \mathrm{cpd}), 114.0 \pm 7.1 \mathrm{~ms}$ $(2 \mathrm{cpd})$ and $129.7 \pm 7 \cdot 1$ (4 cpd). Amplitudes posttreatment were $6.8 \pm 1 \cdot 1 \mu \mathrm{V}(1 \mathrm{cpd}) ; 6.4 \pm 1 \cdot 1(2$ cpd) and $3 \cdot 1 \pm 0.7(4 \mathrm{cpd})$. The mean values of VEPs to $0.5 \mathrm{cpd}$ stimuli was $103.3 \pm 3.1 \mathrm{~ms}$ for latency and $6.6 \pm 1.1 \mu \mathrm{V}$ for amplitude. The ANOVA of pre- vs post-treatment did not show significant variations in amplitude, while the levels of significance for latency were 0.02 for $1 \mathrm{cpd}$ and 0.001 for both 2 and $4 \mathrm{cpd}$ stimuli. The ANOVA with age-matched normal controls showed no differences of latencies and amplitudes when the data collected in these patients before haloperidol administration were compared with control data. When control group data were compared with VEP latencies obtained after haloperidol administration, a significance level of 0.001 was reported for $4 \mathrm{cpd}$. Figure 6 is a scattergram of VEP latencies to the different spatial frequencies of stimulation, prior and after haloperidol administration.

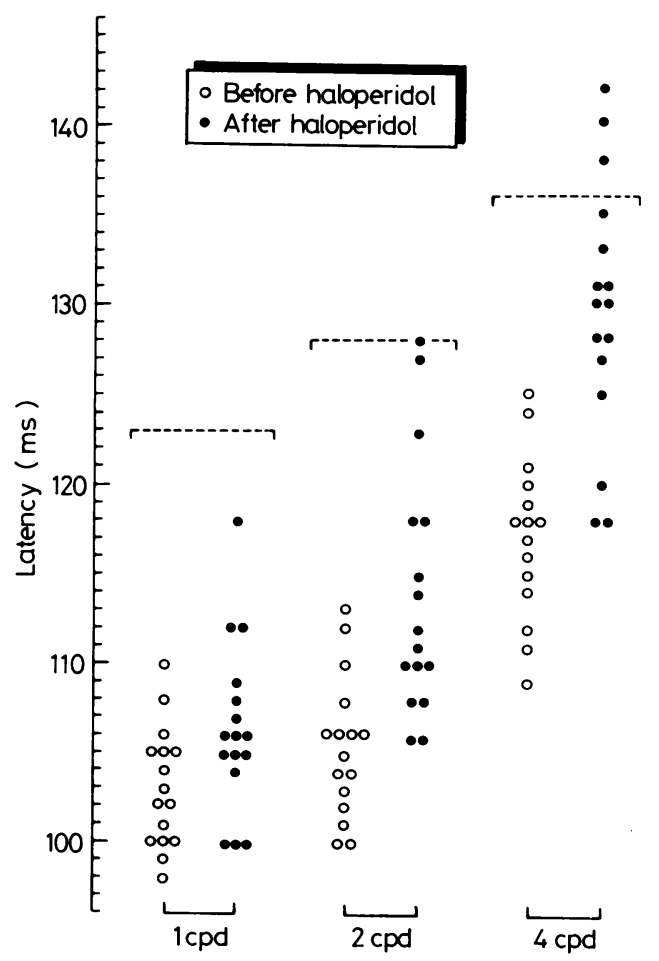

Fig 6 Scattergram of VEP latencies recorded with 1, 2 and 4 cpd stimuli in eight patients before and after haloperidol administration. The dotted lines represent the confidence limit of normal latency for this age range. Note that haloperidol induced the latency delays in three cases, only when 4 cpd stimuli were used. 


\section{Discussion}

The data reported in the present investigation confirm the reports of other researchers, ${ }^{6-12}$ and show that abnormally delayed VEPs can be found in Parkinson's disease and that VEP latencies can be reduced in Parkinson's disease patients by the chronic administration of dopamine precursors. The new findings of this study indicate that the percentage of VEP delays and the amount of latency increments detected in Parkinson's disease patients are dependent on the spatial frequency (that is on the element size of the stimulating pattern) (table 2, fig 1). The VEP latency increases as a function of increasing spatial frequency ${ }^{23-25}$ in normal subjects, and our results show that this latency increase is enhanced in Parkinson's disease and also when dopamine blockers are administered.

We show, moreover, that VEP delays are reduced or suppressed by dopamine precursor therapy and that the dopamine dependent correction of VEP delays is more evident when 4 or 2 cpd stimuli are used rather than $1 \mathrm{cpd}$ (table 2, fig 1).

The reduction of VEP latencies in Parkinson's disease by dopamine precursor treatment is not only found with chronic administration, but can be detected after a single dose of levodopa + carbidopa (table 4, fig 4). Abrupt variations in VEP latencies can also be demonstrated in Parkinson's disease patients experiencing periods of spontaneous fluctuation of clinical symptoms (fig 3 ).

These results agree with our preliminary VEP and pattern electroretinogram (PERG) studies in monkeys treated with 1-methyl, 4-phenyl, 1-2-3-6 tetrahydropyridine (MPTP). ${ }^{26}$ MPTP is a neurotoxic substance inducing a full Parkinsonian syndrome in humans $^{27}$ and other primates. ${ }^{28}$ Following MPTP administration, both VEP and PERG of our monkeys were abnormal to the higher spatial frequencies (2 and $4 \mathrm{cpd})$. These electrophysiological abnormalities, as well as Parkinsonian symptoms, were reversible with levodopa therapy.

The results of our study on haloperidol administration in non-Parkinson's disease patients showed that this dopamine receptor blocking drug increased the latency of VEPs obtained with 2 and 4 cpd stimuli, while the effect on $0.5 \mathrm{cpd}$ and $1 \mathrm{cpd}$ VEPs was less consistent (figs 5,6 ).

This new finding supports the hypothesis that dopamine modifies the processing of VEPs by acting at the synaptic level. ${ }^{29-31}$

The specific sensitivity of VEP changes to the spatial frequency of stimulation in Parkinson's disease and haloperidol treated subjects, which is evident in our results, might suggest that the VEP abnormalities found in our study are dependent on the impairment of dopaminergic neural structures which regulate spatial frequency sensitivity.

A role in shaping the spatial frequency sensitivity was recently assigned to dopaminergic horizontal cells of the retina. ${ }^{32-34}$ The authors showed an effect of dopamine on modulating the receptive field at the cellular level in the retina: by decreasing the level of dopamine, retinal cells become more sensitive to coarser stimuli and less sensitive to finer patterns than they were prior to dopamine depletion. Furthermore, recent psychophysical data collected from Parkinson's disease patients and volunteers after the administration of dopamine and haloperidol showed alterations of the contrast sensitivity specific to spatial frequency. ${ }^{3536}$ Obviously caution is required when extrapolating data from single cells or psychophysical studies to the interpretation of clinical VEP results. Whereas there is now evidence that dopamine is present in the human retina ${ }^{37}$ and that pathological findings extend outside the basal ganglia in Parkinson's disease, ${ }^{38}{ }^{39}$ histochemical investigations of eyes of Parkinson's disease patients are needed to confirm a possible retinal dopaminergic dysfunction in Parkinson's disease.

However, Martres et $a l^{40}$ recently reported that dopaminergic receptors are extensively present in the central nervous system, even in areas in which dopaminergic innervation was not known or completely established. While the existence and the role of dopamine in the retina can explain part of our results, we can not exclude the influence of dopaminergic activity elsewhere in the visual system.

Thus, our studies confirm that non-motor functions can be altered in Parkinson's disease $e^{41-45}$ and that these alterations may vary with time, probably depending on the supply of dopamine. Our results further suggest that VEP studies in Parkinson's disease may be influenced by such factors as the stimulus parameters, the drug therapy, or the clinical condition of the patients. The dynamic relationship of VEP delays to dopamine precursor treatment as well as the selection of the stimulus parameters can explain the poor $^{12}$ or null ${ }^{13-17}$ detection of VEP abnormalities in Parkinson's disease by other researchers. In those studies, the patients were tested during current dopamine precursor therapy ${ }^{131617}$ or temporal relationship between therapy and VEP recording are not specified. ${ }^{12}{ }^{16}$ Moreover, coarse pattern elements of spatial frequency ranging from $1^{13}$ to $0.39 \mathrm{cpd}^{16}$ or flashing light stimulation ${ }^{15}$ were used.

The findings of the present study are not encouraging in respect to the clinical utility of VEP studies in Parkinson's disease. The results of correlating VEP latencies at the various spatial frequencies with the clinical stage of the disease and functional scores of the major symptoms were disappointing. The stage of 
Parkinson's disease ${ }^{21}$ did not significantly correlate with VEP measurements, or with VEP changes after treatment, even though the percentages of VEP abnormalities and changes post-treatment seemed to indicate a difference among the stages (table 3 ).

The finding that delayed VEPs are observed even in the early stages of the disease should also mediate against the hypothesis of VEP alterations being related to the degree of cortical atrophy.

Some authors found correlations between VEP latencies and the disease stage, ${ }^{78}$ while others found inverse correlations, ${ }^{6}$ and still others did not extend their study to the patients rated beyond stage II. ${ }^{910}$

To our knowledge, there are no reports of correlations of VEPs with the clinical symptoms of Parkinson's disease. We measured VEP obtained in untreated and treated conditions and correlated them with clinical scores for bradykinesia, tremor, rigidity and gait as well as with the modifications of these scores after chronic levodopa + carbidopa therapy. Any evidence of correlations between clinical score or treatment dependent clinical modification and VEPs would have been of interest as it might suggest different types of Parkinsonism. A significant correlation was found only for pre-treatment VEP latency vs pre-treatment bradykinesia scores. We consider this result to be spurious, because the bradykinesia correlation was essentially confined to latencies of the left eye alone, and the distribution of delayed VEPs was dispersed over the entire range of clinical scores.

We conclude therefore that none of the signs of Parkinsonism correlate with the VEP evidence of visual system involvement. Moreover, the lack of correlation between VEP abnormalities in the pretreatment state, or VEP changes after acute levodopa + carbidopa administration and the change of clinical scores following chronic levodopa + carbidopa therapy, shows that VEPs can not predict clinical response to dopamine therapy.

The findings that VEPs are not delayed in patients with Parkinsonian syndrome (as in supranuclear progressive paralysis or arteriosclerotic pseudoParkinsonism) nor that the VEP latencies decreased by Sinemet administration (fig 4) might be of clinical interest. We must, however, point out that VEPs are normal in as many as $40-60 \%$ of idiopathic Parkinson's disease patients.

Finally, the finding that the VEP latency increases after the administration of dopamine blockers, which we and others ${ }^{19}$ have reported, suggests that evoked potentials might be useful in identifying and monitoring psychiatric patients at risk for developing pseudo-Parkinsonism or tardive dyskinesia. Unfortunately, the poor correlation between motor abnormalities and VEP alterations in Parkinson's disease patients suggests poor predictability of supersensitivity to psychotropic drugs by VEP measurements

Preliminary results of this study were presented at the Congresses: "Cerebral Pathology in old age", Pavia, Oct. 1982; "Restorative Neurology in Central and Peripheral Nervous System", Venice, May 1983; "Congresso della Societa' Italiana di Neurologia", Parma, Oct. 1983.

We thank Drs MS Marx, M Sivak, and K Bergmann for their helpful comments on the manuscript.

\section{References}

${ }^{1}$ Halliday AM, McDonald WI, Mushin J. Delayed visual evoked response in optic neuritis. Lancet 1972;i:982-5.

${ }^{2}$ Halliday AM, Halliday E, Kriss A, McDonald WI, Mushin J. The pattern evoked potential in compression of the anterior visual pathways. Brain 1976;99:357-74.

${ }^{3}$ Carroll WM, Kriss A, Baraitser M. The incidence and nature of visual pathway involvement in Friedreich's ataxia: A clinical and visual evoked potential study. Brain 1980;103:413-34.

${ }^{4}$ Bird T, Crill WB. Pattern-reversal visual evoked potentials in the hereditary ataxias and spinal degeneration. Ann Neurol 1981;9:243-50.

${ }^{5}$ Livingstone IR, Mastaglia FL, Edis R, Howe JW. Visual involvement in Friedreich's ataxias and hereditary spas- ? tic ataxia. Arch Neurol 1981;38:75-9.

${ }^{6}$ Bodis-Wollner I, Yahr MD. Measurements of visual evoked potentials in Parkinson's Disease. Brain 1978;101:661-71.

${ }^{7}$ Gawell MJ, Das P, Vincent G, Rose FC. Visual and auditory evoked responses in patients with Parkinson's Disease. J Neurol Neurosurg Psychiatry 1981;44:227-32.

${ }^{8}$ Delwaide PJ, Messaona B, DePasqua V. Les potentiels evoques visuel dans la maladie de Parkinson. Rev EEG Neurophysiol 1980;10:338-42.

${ }^{9}$ Kupersmith MJ, Shakin E, Siegel IM, Lieberman A. Visual system abnormalities in patients with Parkinson's Disease. Arch Neurol 1982;39:284-6.

${ }^{10}$ Tartaglione A, Pizio N, Bino G, Spadavecchi L, Favale E. VEP changes in Parkinson's Disease are stimulus specific. J Neurol Neurosurg Psychiatry 1984;47:305-7.

${ }^{11}$ Solazzo D, Carulli O, Alema G. Potenziali evocati visivi (PEV) da Pattern Reversal nel morbo di Parkinson. Incontri di Studio a Tabiano 1983;2:235-40.

12 Regan D, Neima D. Visual fatigue and visual evoked potentials in multiple sclerosis, glaucoma, ocular hypertension and Parkinson's Disease. J Neurol Neurosurg Psychiatry 1984;47:673-8.

${ }^{13}$ Ehle AL, Steward RM, Lellelind NE, Leventhal NA. Normal checkerboard pattern reversal evoked poten- 
tials in Parkinsonism. Electroencephalogr Clin Neurophysiol 1982;54:336-8.

${ }^{14}$ Halliday AM. Evoked Potentials. 1982 Oxford: Churchill Livingstone 120.

${ }^{15}$ Yaar I. The effect of levodopa treatment on the visual evoked potentials in Parkinsonian patients. Electroencephalogr Clin Neurophysiol 1981;50:267-74.

${ }^{16}$ Dinners DS, Luders H, Hanson M, Lesser RP, Klem G. Pattern Evoked Potentials (PEPs) in Parkinson's Disease. Neurology (Cleveland) 1985;35:610-3.

${ }^{17}$ Hansch EC, Syndulko K, Cohen SN, Goldberg ZI, Potvin AR, Tourtellotte WW. Cognition in PD: an eventrelated potential perspective. Ann Neurol 1982;11:599-607.

${ }^{18}$ Mintz M, Tomer R, Radwan H, Myslobodsky MS. Visual Evoked Potentials in Hemiparkinsonism. Electroencephalogr Clin Neurophysiol 1981;52:611-6.

${ }^{19}$ Bodis-Wollner I, Yahr MD, Mylin LH, Thornton J. Dopaminergic deficiency and delayed visual evoked potentials in humans. Ann Neurol 1982;11:478-3.

${ }^{20}$ Clough CG, Bergmann KJ, Yahr MD. Cholinergic and dopaminergic mechanisms in Parkinson's Disease after long-term L-Dopa administration. Advances in Neurology 1984;40:131-40.

${ }^{21}$ Hoehn MM, Yahr MD. Parkinsonism: onset, progression and mortality. Neurology (Minneap) 1967;17:427-42.

${ }^{22}$ Klawans HL. Behavioral alterations and the therapy of Parkinsonism. Clin Neuropharmacology 1982;5:529-37.

${ }^{23}$ Jones R, Keck MJ. Visual evoked response as a function of grating spatial frequency. Invest Ophthalmol Vis Sci 1978;17:652-9.

${ }^{24}$ Skrandies W. Scalp potential fields evoked by grating stimuli: effects of spatial frequency and orientation. Electroencephalogr Clin Neurophysiol 1984;58:325-32.

${ }^{25}$ Plant GT, Zimmern RL, Durden K. Transient visual evoked potentials to the pattern reversal and onset of sinusoidal grating. Electroencephalogr Clin Neurophysiol 1983;56:147-58.

${ }^{26}$ Onofrj M, Bodis-Wollner I, Ghilardi MF, Marx M, Glover A. Pattern vision in monkeys with Parkinsonism: a stimulus specific effect of MPTP on retinal and cortical responses. In: Markey SP, Castagnoli N, Trevor A, Kopin IJ eds. "MPTP: a Neurotoxin Producing a Parkinsonian Syndrome”. California: Academic Press, in press.

${ }^{27}$ Ballard PA, Tetrud JW, Langston JW. Permanent human Parkinsonism due to 1-methyl, 4-phenyl, 1-2-3-6-tetrahydropyridine (MPTP): seven cases. Neurology (Cleveland) 1985;35:949-56.

${ }^{28}$ Burns RS, Chieuh CC, Markey SP, Ebert MH, Jacobowitz DM, Kopin JJ. A primate model of Parkinsonism: selective destruction of dopaminergic neurons in the pars compacta of the substantia nigra by $\mathrm{N}$ methyl 4-phenyl 1-2-3-6-tetrahydropyridine. Proc Natl Acad Sci USA 1983;80:4546-50.

${ }^{29}$ Dyer RS, Howell WE, MacPhail RC. Dopamine depletion slows retinal transmission. Exp Neurol
1981;71:326-40.

${ }^{30}$ Bodis-Wollner I, Onofrj M. System diseases and visual evoked potential diagnosis in neurology: changes due to synaptic malfunction. Ann NY Acad Sci 1982;388:327-48.

${ }^{31}$ Onofrj M, Bodis-Wollner I. Dopaminergic deficiency causes delayed visual evoked potentials in rats. Ann Neurol 1982;11:484-90.

${ }^{32}$ Cohen JL, Dowling JE. The role of retinal interplexiform cells: effect of 6-hydroxydopamine on the spatial properties of carp horizontal cell. Brain Res 1983;264:307-10.

${ }^{33}$ Teranishi T, Negishi K, Kato S. Regulatory effect of dopamine on spatial properties of horizontal cells in carp retina. J Neurosci 1984;4:1271-80.

${ }^{34}$ Piccolino M, Neyton J, Gerschenfeld HM. Decrease of gap junction permeability induced by dopamine and cyclic adenosine $3^{\prime}, 5^{\prime}$-monophosphate in horizontal cells of turtle retina. $J$ Neurosci $1984 ; 4: 2477-88$.

${ }^{35}$ Bodis-Wollner I, Mitra S, Bobak P, Guillory S, Mylin L. Low frequency distortion in spatio-temporal threshold surface in Parkinson's Disease. Invest Ophthalmol Visual Sci Suppl 1984;25:313.

${ }^{36}$ Domenici L, Trimarchi C, Piccolino M, Fiorentini A. Effect of dopaminergic drugs on human contrast sensitivity. 7th European Conference on Visual Perception. Perception Suppl 1984;13:A38.

${ }^{37}$ Frederich JM, Rayborn ME, Laties AM, Lam DMK, Hollofield JG. Dopaminergic neurons in the human retina. J Comp Neurol 1982;210:65-79.

${ }^{38}$ Barbeau A, Campanella G, Butterwoth RF, Yamada K. Uptake and efflux of 14-C-Dopamine in platelets: evidence for a generalized defect in Parkinson's Disease. Neurology (Minneap) 1975;25:1-9.

${ }^{39}$ Hakim AM, Mathieson G. Dementia in Parkinson's disease: a neuropathological study. Neurology (Minneap) 1979;29:1209-14.

${ }^{40}$ Martres MP, Bouthenet ML, Sales N, Sokoloff P, Schwarzt JC. Widespread distribution of brain dopamine receptors evidenced with [125 I] Iodosulpride, a lightly selective ligand. Science 1985;228:752-6.

${ }^{41}$ Snider SR, Fahn S, Isgreen WP, Cato LJ. Primary sensory symptoms in Parkinsonism. Neurology (Minneap) 1976;26:423-9.

${ }^{42}$ Koller WC. Sensory symptoms in Parkinson's disease. Neurology (Cleveland) 1984;34:597-8.

${ }^{43}$ Ansari KA, Johnson A. Olfactory function in patients with Parkinson's Disease. J Chronic Dis 1975;28:493-7.

${ }^{44}$ Brown RG, Marsden CD, Quinn N, Wyke MA. Alterations in cognitive performance and affect arousal state during fluctuations in motor function in Parkinson's Disease. J Neurol Neurosurg Psychiatry 1984;47: 454-65.

${ }^{45}$ Boller F, Passafire D, Keefe NC, Rogers K, Morrow L, Kin Y. Visuospatial impairment in Parkinson's Disease. Arch Neurol 1984;41:485-90. 